\title{
EXPERIMENTAL STUDY ON TOOL WEAR IN MICROTURNING OF OFHC COPPER
}

\author{
Ranjith Kumar P.', Gowri S. ${ }^{2}$, Krishnamurthy R. ${ }^{3}$ \\ ${ }^{1}$ Research scholar, Department of Manufacturing Engineering, Anna University, Chennai, India \\ ${ }^{2}$ Department of Manufacturing Engineering, Anna University, Chennai, India \\ ${ }^{3}$ Department of Mechanical Engineering, Indian Institute of Technology Madras, Chennai, India \\ Email: 'ranjjith@rediffmail.com
}

\begin{abstract}
This paper presents experimental results of microturning of oxygen free high conductivity (OFHC) copper rods using cermet inserts of $0.1 \mathrm{~mm}$ nose radius as cutting tool. Machining was done in DT-110 Integrated multiprocess micromachine tool. Full factorial experiments were conducted with various combinations of cutting speed, feed and depth of cut. Tool wear for different conditions were measured offline and also acoustic emission signals (AE rms) were recorded. Variations of tool wear with time and correlation between AE rms and tool wear were studied. Good correlation was observed between AE rms and tool wear. Also scanning electron microscope images of worn out inserts were analyzed to ascertain the wear mechanisms. It was found that mostly steady machining can be obtained with medium speed and feed.
\end{abstract}

Keywords: Micromachining, Microturning, Tool wear, Acoustic emission, OFHC copper

\section{INTRODUCTION}

Microcutting, being an ultra-precision machining process, is becoming increasingly important for its capability of producing parts with three dimensional features ranging from a few microns to a few hundred microns, in a wide range of materials. The technologies that have been utilized in micromachining are existing technologies adapted to the miniaturization of structures, devices and systems [1]. There are number of issues in micro-scale machining that are fundamentally different from macro-scale machining [2]. They include differences in the underlying mechanisms resulting in changes in the chip formation process, machining forces, specific energy and surface finish. At micrometer range of material removal, the well known size effect is observed where the specific cutting energy/force increases non-linearly with reduction in uncut chip. However, there exists not much consensus on a phenomenological explanation of microcutting processes [3]. Although geometric and material capabilities of micromachining have been demonstrated by various researchers $[4,5]$, industrial application of micromachining has been hindered by the lack of experience and knowledge on the micro-machinability of materials. Because of these differences between conventional machining and micromachining, the existing knowledge and experience cannot be directly applied to the micron scale. To enable effective industrial application of micromachining, there is an urgent need for concerted experimental investigation of micromachining processes [6-8]. Microturning is a mechanical micromachining process which is an attempt to miniaturize the conventional turning process while operating at the micron scale of parameters to produce micro components such as micro electrodes and microshafts [9].

\section{MICROTURNING}

Microturning, a microcutting process is a conventional material removal process that has been miniaturized. Form accuracy and dimensional stability are very important for micromachined parts [10] which are affected by tool wear. As in the case of conventional machining process, feed rate and cutting speed have more significance on tool flank wear. Literatures show that not enough research works have been carried out on wear studies in microturning. The survey on the available limited literatures on microturning indicates the possible wear modes and associated mechanisms in micromachining. The studies on monitoring of tool wear during machining have illustrated the applicability of acoustic emission in sensing tool wear [11]. However, enough data on micromachinability of OFHC copper and related materials are not available and also only a limited knowledge on the wear of tools especially in micromachining environment is available. For a better understanding of response of OFHC copper to micromachining environment, detailed experimental study has been carried out and reported here.

\section{EXPERIMENTATION DETAILS}

\section{A. Machine Tool}

The machine tool used for performing microturning is MIKROTOOLS DT-110 Micromachine tool (Figure 1). It is a 3-axis automatic Multiprocess integrated machining system for performing various micromachining operations such as Micro-Turning, Micro-Milling, Micro-Grinding, Micro-Electro Discharge Machining, Micro Wire-Electro Discharge Machining, Micro-Electro Discharge Grinding and Micro-Electro Chemical Machining. 


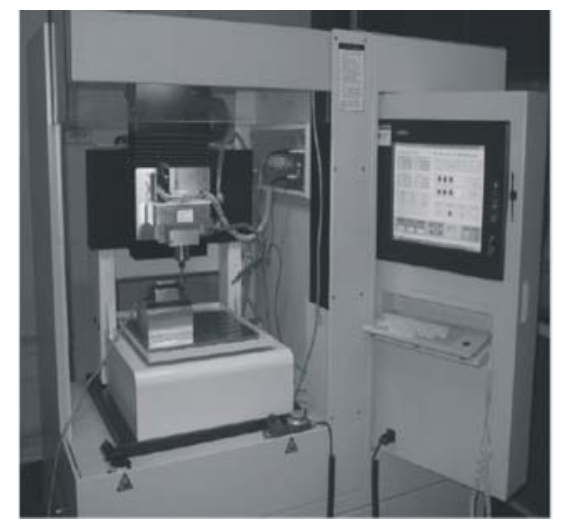

Fig. 1 Micromachine tool

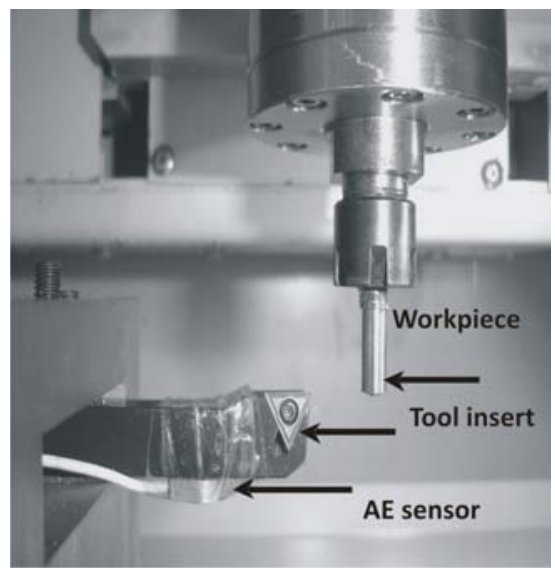

Fig. 2. AE sensor setup

\section{B. Experimental Design}

The experimental design involves the selection of suitable levels for the machining parameters i.e. speed, feed, depth of cut. Based on the machine tool, cutting tool and workpiece, parameters are selected as listed in Table 1. The parameters each at three levels would result in 33 $=27$ combinations and full factorial experiment was conducted.

\section{Workpiece material and Cutting Tool}

OFHC copper is important for applications in optics, laser and micro-electronic fields. Hence OFHC copper rods of commercial grade purity are used as work material. The Cermet insert of SUMITOMO make with $0.1 \mathrm{~mm}$ nose radius, 7 front clearance and 10 rake angle is used as cutting tool. The tool shank used was Sumitomo type STGCR1010-09 mini tool holder.

Unlike the conventional turning process, in this microturning process, the work piece is clamped vertically in the spindle unit which facilitates the $X$ and $Z$ axis movements and the tools are fixed to the machine table (Yaxis).
Table 1. Parameter Levels

\begin{tabular}{|c|l|c|c|c|}
\hline SI.No & \multicolumn{1}{|c|}{ Parameter } & Level 1 & Level 2 & Level 3 \\
\hline 1 & $\begin{array}{l}\text { Cutting Velocity }(\mathrm{V}) \\
(\mathrm{m} / \mathrm{min})\end{array}$ & 24 & 32 & 40 \\
\hline 2 & $\begin{array}{l}\text { Feed(S) } \\
(\mu \mathrm{m} / \mathrm{rev})\end{array}$ & 2 & 8 & 14 \\
\hline 3 & $\begin{array}{l}\text { Depth of cut(a) } \\
(\mu \mathrm{m})\end{array}$ & 5 & 10 & 15 \\
\hline
\end{tabular}

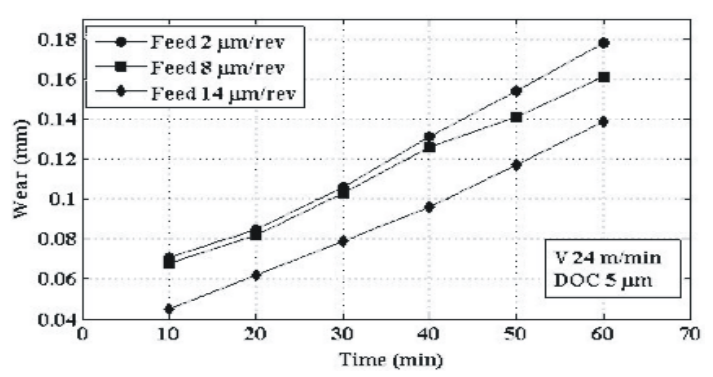

(a)

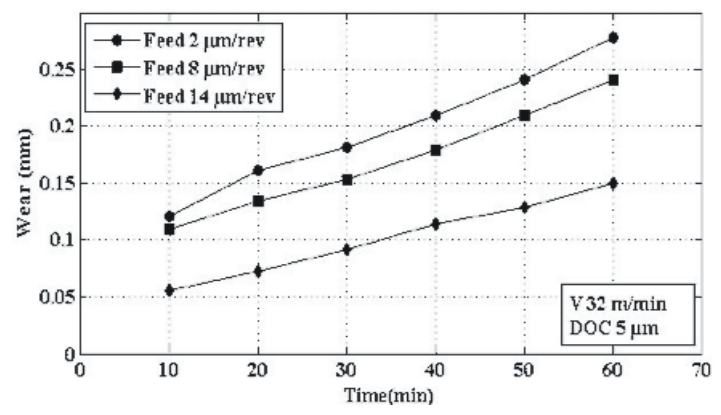

(b)

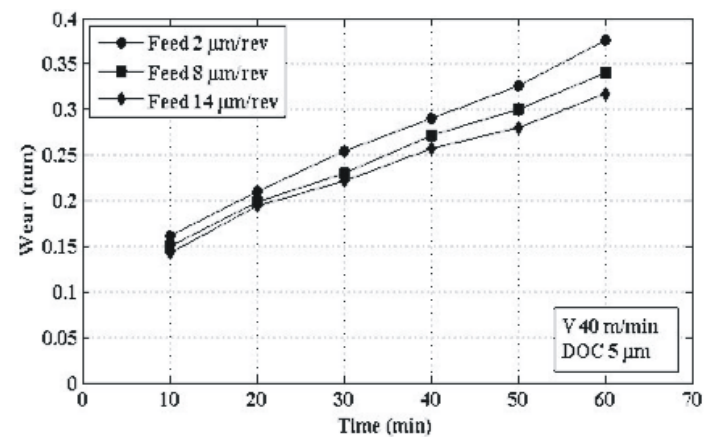

(c)

Fig. 3. Typical parametric influences on flank wear for depth of cut of $5 \mu \mathrm{m}$

The depth of cut and feed motions are imparted by moving the work piece along the $\mathrm{X}$ and $\mathrm{Z}$-axis respectively. 


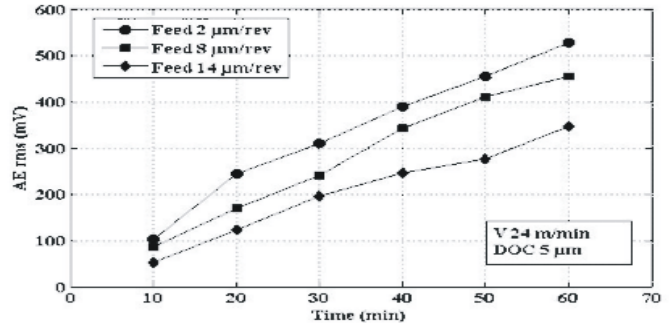

(a)

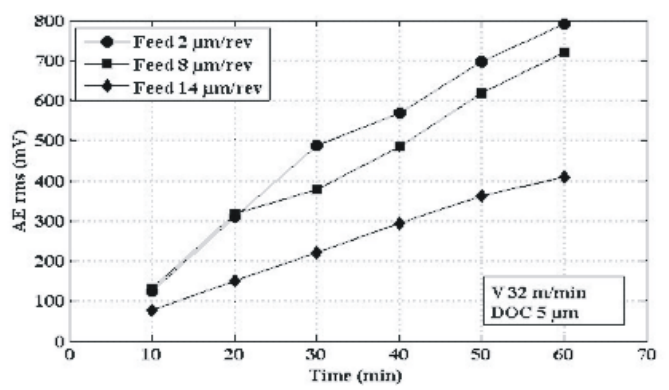

(b)

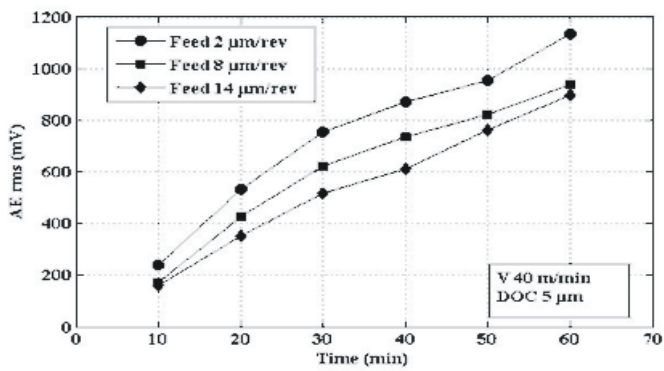

(c)

Fig. 4. Typical parametric influences on AE rms for depth of cut of $5 \mu \mathrm{m}$

\section{Acoustic Emission Monitoring}

The AE signals were sensed using piezo-electric sensor fixed to the tool holder (Figure 2) and they were amplified by a pre-amplifier. These amplified signals were then fed to the data acquisition system, AET-5500, for processing and storage.

\section{E. Experimental Procedure}

A fresh cermet tool is used to machine the copper rods under different cutting conditions. For different cutting condition $A E$ rms is recorded and tool flank wear is measured at every 10 minutes and each experiment is done for duration of 60 minutes and no coolant was used during microturning process.

\section{RESULTS AND DISCUSSIONS}

\section{A. Observations on flank wear}

Typical observed parametric influence on flank wear is illustrated in Figure 3. Figure 3.a shows progression of flank wear with lower depth of cut of $5 \mu \mathrm{m}$. It is observed that as the feed rate increases from $2 \mu \mathrm{m} / \mathrm{rev}$ to $8 \mu \mathrm{m} / \mathrm{rev}$ the wear rate decreases. For Feed rate of $14 \mu \mathrm{m} / \mathrm{rev}$ lower wear rate was observed over other two feed rate. With low feed rate, the cutting wedge tends to rub over the work surface which leads to higher wear rate. As the feed increases, better cutting takes place which leads to reduced wear rate. Hence for controlled wear conditions, the feed rate should be in the range of $8-14 \mu \mathrm{m} / \mathrm{rev}$.

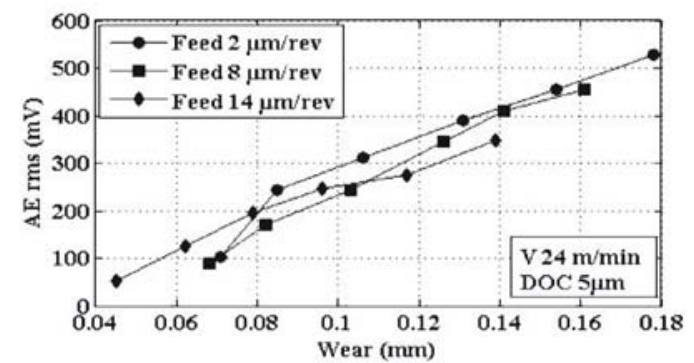

(a)

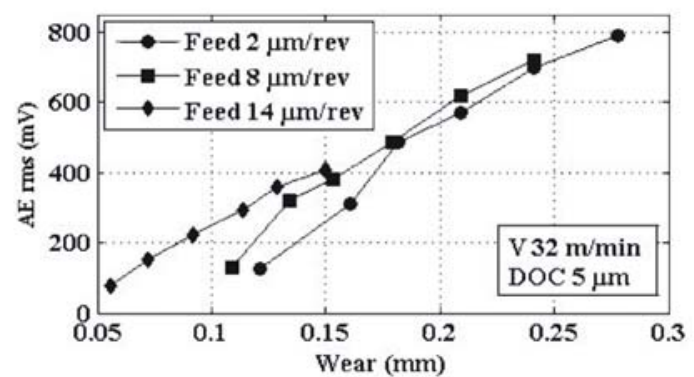

(b)

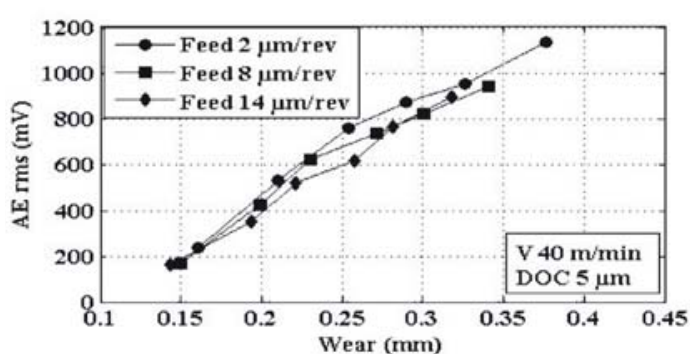

(c)

Fig. 5. Typical parametric influences on $A E$ rms and wear for depth of cut of $5 \mu \mathrm{m}$ 


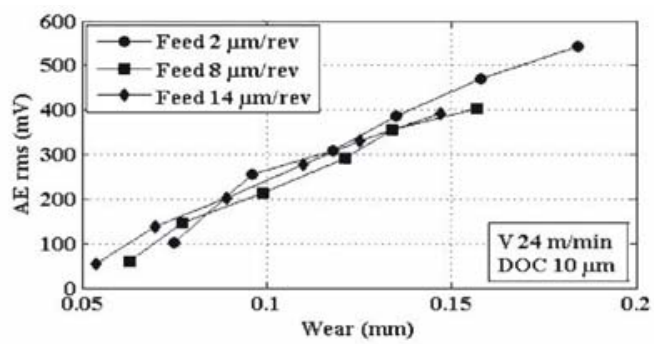

(a)

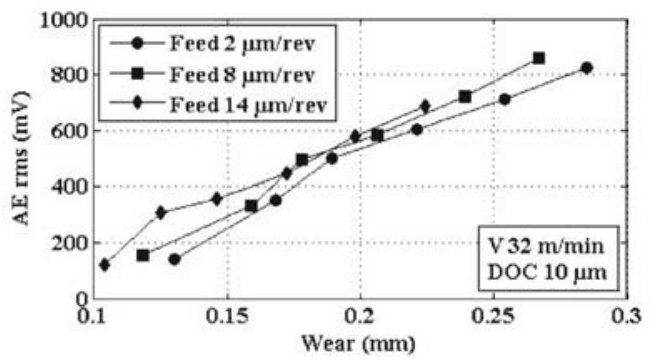

(b)

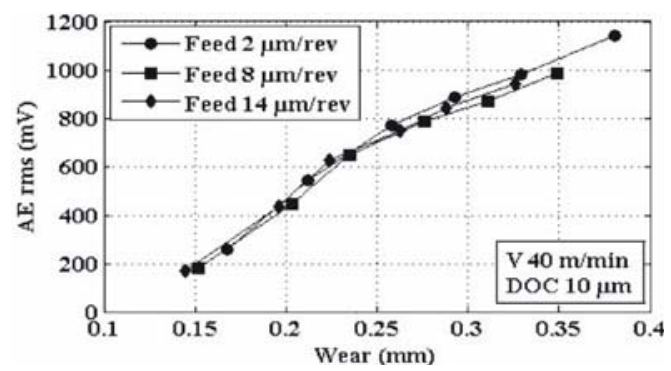

(c)

Fig. 6. Typical parametric influences on $A E$ rms and wear for depth of cut of $10 \mu \mathrm{m}$

For the entire duration of machining progressive wear rate was observed. For lower feed rate of $2 \mu \mathrm{m} / \mathrm{rev}$ and medium feed rate of $8 \mu \mathrm{m} / \mathrm{rev}$ close wear rate was observed between 10-40 minutes.

Figure 3.b shows tool wear characteristics for speed of $32 \mathrm{~m} / \mathrm{min}$. Similar trend as in the earlier case was observed here also. Higher feed rate of $14 \mu \mathrm{m} / \mathrm{rev}$ results in lower order of wear rate. The wear rate increases with increase in cutting speed. Figure 3.c. presents the observations on tool wear with further increase in speed of machining. In this case also higher feed rate of $14 \mu \mathrm{m} / \mathrm{rev}$ results in lower wear rate. For the entire feed rate closer wear rate was observed during 10-40 minutes. It is also observed that unlike the feed rate, with cutting speed, the tool wear increases, attributable to thermal dominant wear of cutting tool.

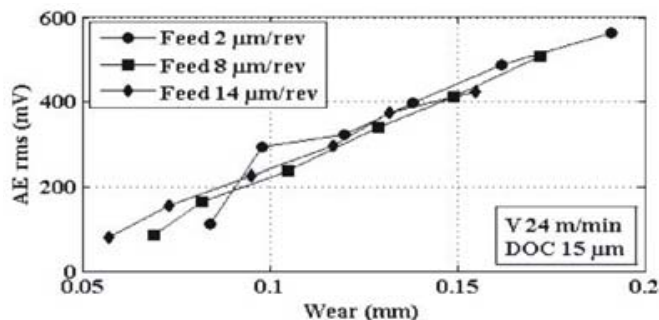

(a)

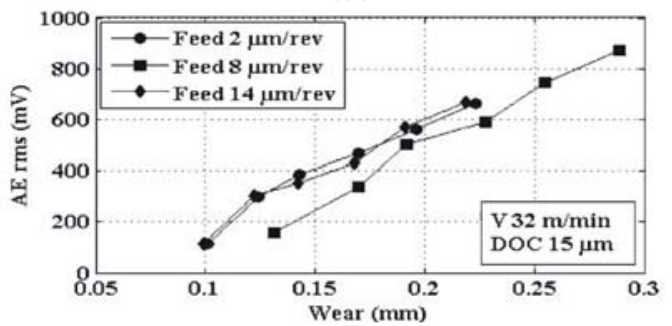

(b)

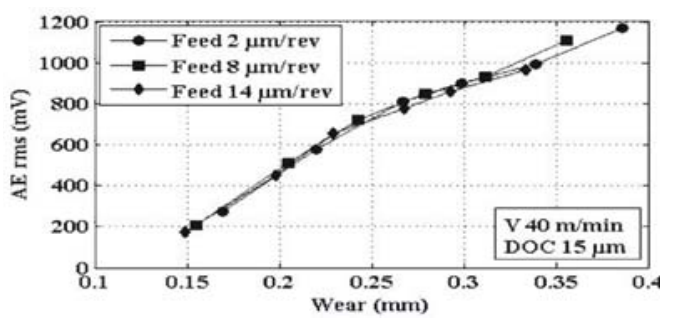

(c)

Fig. 7. Typical parametric influences on $A E$ rms and wear for depth of cut of $15 \mu \mathrm{m}$

\section{B. Acoustic Emission observation}

The response of a material to different environmental conditions can be reliably evaluated by monitoring acoustic emission emitted from the material. In the present study, the response of the tool to machining environment has been assessed by on-line monitoring of the acoustic emission from it.

The monitored signal was characterised in terms of its root mean square value ( $A E$ rms ) normally relating to the energy released value. Typical monitored parametric influence on $A E$ rms is presented in Figure 4 . It is observed that $A E$ rms progressively increases with the time of machining and also with the speed of machining. With high feed rate, there is a reduction in AE rms. The reduction in $\mathrm{AE}$ rms with feed rate is in accordance with reduction in wear with feed rate i.e controlled tool wear results in controlled energy release rate.

\section{AErms on Flank wear}

Typical monitored influence of tool wear on AE rms is illustrated in the Figures 5, 6and 7. Referring to Figure 5 it 
is seen that with wear of tool a rise in $A E$ rms occurs. Also it is seen that around $300 \mathrm{mv}$, a change in the trend of variation of $A E$ rms occurs, also it is mostly about 0.08 $0.15 \mathrm{~mm}$ of tool wear depending on the machining conditions. Similar trend can be seen in Figure 6, for depth of cut of $10 \mu \mathrm{m}$. With depth of cut, relatively larger acoustic emission can be seen. Almost similar trend of variation in $\mathrm{AE}$ rms can be seen in Figure 7 also. It is seen that despite the cutting conditions, with flank wear of around 0.1-0.15 $\mathrm{mm}$, identical acoustic emission energy release occur. Thus it can be inferred that there is a good correlation existing between tool wear and $\mathrm{AE}$ rms.

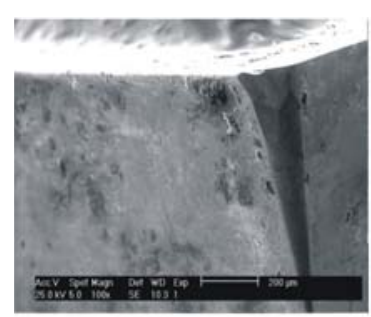

(a)

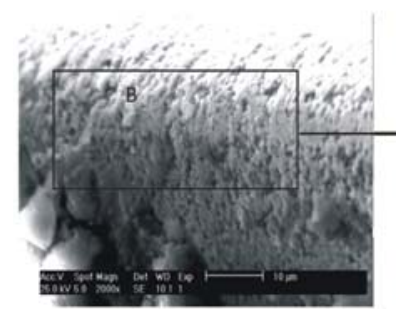

(c)

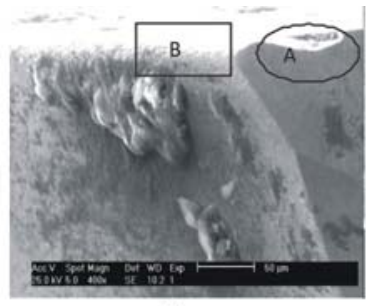

(b)

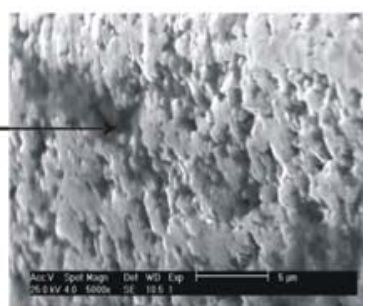

(d)
Fig. 8. SEM Images of cermet insert

( $V=24 \mathrm{~m} / \mathrm{min}, \mathrm{S}=2 \mu \mathrm{m} / \mathrm{rev}, \mathrm{a}=5 \mu \mathrm{m}$ )

\section{Micrograph observations}

Micrographs of worn out cermet tool exposed to micromachining of OFHC copper with cutting conditions of $\mathrm{V}=24 \mathrm{~m} / \mathrm{min}, S=2 \mu \mathrm{m} / \mathrm{rev}$ and $\mathrm{a}=5 \mu \mathrm{m}$ are shown in Figure 8 .

Typical triangulation wear out in nose region can be seen in Figure 8.a. This is attributable to the cutting conditions (feed and depth of cut) mostly fall within the nose geometry. The sliding of the finished machined work surface over the tool flank below the nose, results in the triangulation mode. Also due to dominant dwelling in the cutting wedge and associated plowing on to the work material, the cutting wedge would have oscillated, resulting in the formation of a dent $(A)$ over the rake face.

Figure 8.b also indicates the occurrence of secondary grooving wear. During machining, the cutting wedge normally experiences maximum temperature over the depth of cut region, nose tip and the secondary flank behind the nose. This can result in possible oxidation of the tool material yielding to wear over secondary cutting edge.
Typical wear on secondary edge, termed as secondary grooving wear can be seen in the Figure 8.b. Magnified view of the grooved region (Figure 8.c \& Figure 8.d) shows interior flow of carbide, with removal of binder phase. Formation of carbide skeleton is attributable to interior sliding of the tool flank over secondary cutting region behind the nose. Sliding of the material over the tool flank has resulted in transport of the material down the flank. This is similar to tear drop formation in coatings exposed to sliding wear.

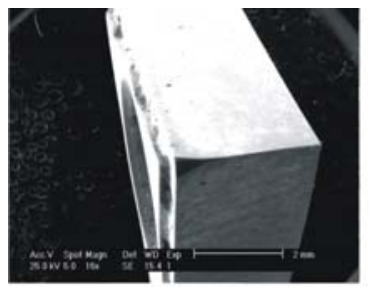

(a)

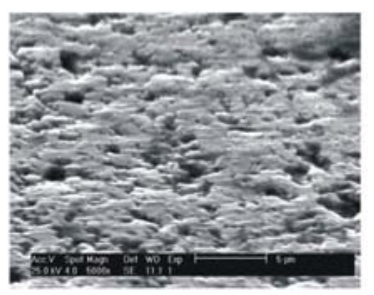

(c)

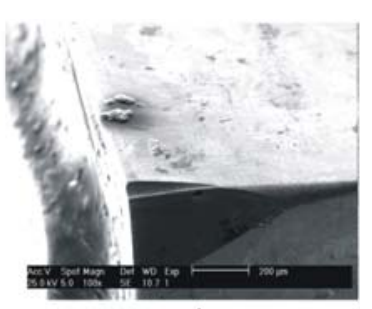

(b)

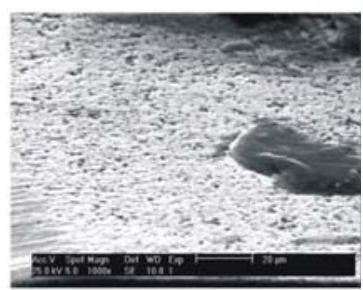

(d)
Fig. 9. SEM images of cermet inserts $(V=32 \mathrm{~m} / \mathrm{min}, S=8 \mu \mathrm{m} / \mathrm{rev}, \mathrm{a}=10 \mu \mathrm{m})$

Typical macrographs of worn out cermet tool machining copper $(\mathrm{V}=32 \mathrm{~m} / \mathrm{min}, S=8 \mu \mathrm{m} / \mathrm{rev}$ and $a=10 \mu \mathrm{m})$ are illustrated in Figure 9. It is seen that the tool has undergone relatively wider triangulation nose wear, with a small order deformation at the rake face. Interior sliding of the work hardened machined surface over the tool flank has resulted in a textured surface with elongated grains. The material interaction under interior sliding is associated with frictional heating, possible thermal softening and deformation of the surface material over the tool flank (Figure 9.b). Magnified view of worn-out tool flank region (Figure 9.c) shows material sliding over flank surface with discrete pull out. Magnified view of the nose wear region (Figure 9.d) shows that tool material over the flank in the nose region has been glazed with localized material pull out.

Abrasion of the texture seen in the flank region can be attributed to possible oscillation of the tool tip resulting in a mild burnished texture. 


\section{CONCLUSION}

From the present study, the following conclusions are as follows:

- In the present study of micro machining of OFHC copper the cutting is mostly restricted to nose portion with cutting edge radius playing a significant role on tool performance. Thus, feed rate proportional to edge radius $(14 \mu \mathrm{m})$ have resulted in good machining performance.

- Finer feed facilitates plowing, resulting the higher order wear and with higher feed rate, reduced order of tool wear occurs.

- Despite the cutting conditions, $0.1-0.15 \mathrm{~mm}$ of tool wear results in almost identical $A E$ rms.

- The observation on $\mathrm{AE}$ rms indicates a progressive rise in $A E$ rms with tool wear and good correlation exists between tool wear and $A E$ rms. Hence $A E$ rms could be used for online monitoring of tool wear in microturning of OFHC copper. C u t t ing to o I exhibits mostly triangulation mode of wear over the nose region, with secondary grooving behind the nose.

\section{REFERENCES}

[1] Chae, J., Park, S.S., and Freiheit, T., 2005, 'Investigation of micro-cutting operations', International Journal of Machine Tools and Manufacture, Vol.30, pp. 1-20.

[2] Ikawa, N., Donaldson, R. R., Komanduri, R., Koenigm, W., Aachen, T. H., McKeown, P. A., Moriwaki, T., and Stowers I. F.,1991, 'Ultraprecision Metal Cutting, The Past, the Present, and the Future', Anals of CIRP., vol 40, pp. 587-594.

[3] Lee, K., and Dornfeld, D. A., 2002, 'An Experimental Study on Burr Formation in Micro Milling Aluminum and Copper', Transactions of AMRI/SME, vol 30, pp.1-8.
[6] Lucca, D.A., Seo, Y.W., Rhorer, R.L., and Donaldson, R.R.,1994, 'Aspects of surface generation in orthogonal ultraprecision machining', Anals of CIRP, Vol. 43(1), pp.43-46

[7] Melkote, S.N., and Endres, W.J.,1998, 'The importance of including size effect when modeling slot millin', Journal of Manufacturing science and Engineering, Vol. 120(1), pp.68-75

[8] Sinan Filiz., Caroline M Conley., Matthew B Wasserman., and Burak Ozdoganlar, N., 2007, 'An experimental investigation of micromachinability of copper 101 using tungsten carbide micro-endmills' International Journals of Machine Tools and Manufacture, Vol. 47, pp.1088-1100

[9] Azizur Rahman, M., Rahman, M., Senthil Kumar, S., and Lim, H.S., 2005, 'CNC microturning: an application to miniaturization', International Journal of Machine Tools and Manufacture, vol. 45, pp 631 639.

[10] Gowri, S., Ranjith Kumar, P., Vijayaraj, R., and Balan, A.S.S., 2007, 'Micromachining: Technology for the Future', International Journal of Materials Materials and Structural Integrity, Vol.1/2/3, pp.161179

[11] Moriwaki, T., and Tobito, M.,1988, 'New approach to automatic detection of life of coated tool based on acoustic emission measurement', American Society of Mechanical Engineers, Production Engineering Division (Publication) Vol 33, pp 75-82.

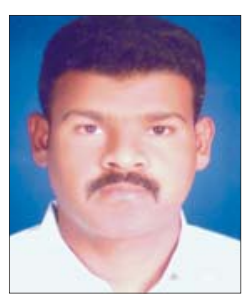

P.Ranjith kumar is a research scholar in the field of Micromachining at the College of Engineering, Anna University, Chennai. He is a post graduate in Production Engineering from PSG college of Technology and a graduate in Mechanical Engineering from Bharathidasan University. He has several publications at National and International level to his credit. 